\title{
The increasing prevalence of non-communicable diseases in low-middle income countries: the view from Malawi
}

This article was published in the following Dove Press journal:

International Journal of General Medicine

\author{
Matthew Gowshall ${ }^{1,2}$ \\ Simon D Taylor-Robinson' \\ 'Division of Digestive Health, \\ Department of Surgery and Cancer, \\ Imperial College London, London, \\ UK; ${ }^{2}$ Barts and the London School of \\ Medicine and Dentistry, London, UK
}

Correspondence: Simon D

Taylor-Robinson

Division of Digestive Health, Department of Surgery and Cancer, Imperial College London, St Mary's Hospital, I0th Floor QEQM Wing, Praed Street, London W2 INY, UK

Tel +44207886 6454

Fax +44 2077249369

Email s.taylor-robinson@imperial.ac.uk

Matthew Gowshall

Barts and the London School of Medicine and Dentistry, Garrod Building, Turner Street, Whitechapel, London EI 2AD, UK

Tel +44782 3698188

Email matthewgowshall@doctors.org.uk

\begin{abstract}
Non-communicable diseases (NCDs) are the leading cause of death globally, the majority of these being due to cardiovascular disease, cancer, chronic respiratory diseases, or diabetes. Mortality from many NCDs continues to increase worldwide, with a disproportionately larger impact in low-middle income countries (LMIs), where almost 75\% of global deaths occur from these causes. As a low-income African country that consistently ranks amongst the world's poorest nations, Malawi as a case study demonstrates how transition due to societal change and increasing urbanization is often accompanied by a rise in the rate of NCDs. Other factors apart from changing lifestyle factors can explain at least some of this increase, such as the complex relationship between communicable and NCD and growing environmental, occupational, and cultural pressures. Malawi and other LMIs are struggling to manage the increasing challenge of NCDs, in addition to an already high communicable disease burden. However, health care policy implementation, specific health promotion campaigns, and further epidemiological research may be key to attenuating this impending health crisis, both in Malawi and elsewhere. This review aims to examine the effects of the major NCDs in Malawi to help inform future public health care policy in the region.
\end{abstract}

Keywords: cancer, chronic respiratory disease, cardiovascular disease, diabetes, non-communicable diseases, Malawi

\section{Introduction}

Non-communicable diseases (NCDs) are globally responsible for more deaths than all other causes combined, with 4 NCDs (cardiovascular disease [CVD], cancer, chronic respiratory diseases [CRD], and diabetes) responsible for $84 \%$ of this mortality.

Almost three quarters of deaths from NCDs occur in low-middle income countries (LMIs) that already experience challenges in managing significant epidemics of infectious disease such as HIV/AIDS and tuberculosis (TB). With many LMIs undergoing rapid epidemiological transition, the emergence of NCDs as a major cause of death risks overwhelming their health systems with a double burden of disease. ${ }^{1}$

\section{NCDs in Malawi}

Malawi is a small country in South-Eastern Africa with approximately 17 million people and consistently ranks amongst the world's poorest nations. ${ }^{2}$ NCDs are estimated to account for $28 \%$ of deaths in Malawi, a figure that continues to rise in countries throughout Sub-Saharan Africa (SSA). ${ }^{1,3}$ Trends in NCDs and factors associated with their development in Malawi are discussed in the following sections. By examining 
their effects, this review aims to raise awareness of this bourgeoning issue in LMIs and help to inform future public health care policy.

\section{Cardiovascular disease}

CVD (including peripheral vascular disease and stroke) has a prevalence of $8.9 \%$ in Malawi and is responsible for $12 \%$ of all deaths. There is a higher age-standardized mortality rate for CVD in Malawi than in many developed countries, including the UK which has an ASMR of 100-175 per 100,000 compared to Malawi's $250-325 .{ }^{4}$ When using age adjusted incidence rates, Malawi also has a greater rate than the UK of both ischaemic heart disease (2166.8 per 100,000 population vs 1098.6) and stroke (1550.1 vs 452.5). ${ }^{5}$ A 2009 STEPwise approach to surveillance (STEPS) survey examined the prevalence of some cardiovascular risk factors in a Malawian population and reported that despite high CVD mortality, many "traditional" risk factors remain relatively uncommon in the Malawian adult population. The prevalence of obesity $(7.4 \%)$, raised cholesterol $>5 \mathrm{mmol} / \mathrm{L}(8.7 \%)$, and smoking $(14.1 \%)$ are low, especially in comparison to the figures from the high-income Western countries such as the UK $\left(26.9 \%, \sim 55.5 \%\right.$, and $17.2 \%$ respectively). ${ }^{6-9}$

However, some of these figures mask statistically significant sex disparities $(p<0.05)$, with obesity rates in women over 3 times the rate in men $(7.3 \%$ vs $2.0 \%)$ and contrariwise for smoking where over a quarter of men (25.9\%) were smokers compared to only $2.9 \%$ of women. The appreciation of these significant differences between demographic groups is essential when considering data regarding NCDs in LMIs to help explain high disease incidence in the setting of apparently low risk factor prevalence. ${ }^{9}$

Hypertension is highly prevalent in Malawi with nearly a third of 25- to 64-year-olds having raised blood pressure or taking antihypertensive medication. ${ }^{9}$ This is consistent with data that suggest an increasing prevalence throughout the African region with a marked rural-urban gradient implicating changes in lifestyle as a key contributor. ${ }^{10}$ Figure 1 demonstrates how age-standardized prevalence rates of hypertension in Malawi and SSA have increased over the past 40 years and now exceed the falling rates in high-income Western countries. ${ }^{11,12}$

The global risk factor analysis carried out by the INTERSTROKE study estimated the population attributable risk resulting from hypertension for all types of stroke to be $90.3 \% .^{13}$ This may help to explain the WHO statistics that attribute the majority of Malawi's CVD mortality to stroke; $5.7 \%$ of all deaths, compared to $3.3 \%$ for ischemic heart disease. One study from a large tertiary hospital in the northern region of Malawi reported that patients with hypertensive heart disease accounted for almost a quarter (24\%) of those attending outpatient cardiology clinics. ${ }^{14,15}$

Many studies have shown preponderance for people of Afro-Caribbean ethnicity to develop hypertension and hypertension-related complications earlier and more frequently than Caucasian people, which are attributed to several proposed physiological differences. These include a reduced suppression of the renin-angiotensin-aldosterone system in the setting of high sodium intake and a lower threshold for pressure-mediated vascular dysfunction. ${ }^{15}$ Studies demonstrating these ethnic differences have reported a higher stroke rate in African participants but a lower risk of coronary artery disease. ${ }^{16,17}$ However, these studies are often confounded by marked socioeconomic differences between the 2 groups.

Smoking-related mortality from CVD in Malawi has increased by $20 \%$ over the 23 -year period from 1990 to 2013 , though this in fact constituted a $31 \%$ increase in males and a $3 \%$ decrease in females. Despite these figures - and despite a commensurate increase in CVD mortality - CVD mortality rate in men is less than in women. ${ }^{4}$ This indicates that cardiovascular risk in Malawi is truly multifactorial, whereby certain factors such as obesity and raised cholesterol that are significantly more prevalent in women may outweigh the increased risk in men caused by a higher smoking rate. The poor affordability of cigarettes and the typically high nicotine content of Malawian tobacco mean that fewer cigarettes are smoked per day by the average "smoker" than in a developed country (rarely more than 5). This may make smoking tobacco a weaker risk factor for CVD in this population. ${ }^{9,18}$

Dietary factors like low seed, nut, and vegetable intake and high sodium intake are regarded as risk behaviors contributing to the increase of CVDs across SSA. ${ }^{19,20}$

Sodium intake is increasing, with every published sodium consumption study in Tanzania (with which Malawi shares a border to the north-east) reporting consumption greater than the WHO set guidance limits of $2 \mathrm{~g}$ /day. Data from Malawi are scarce, with only 1 study published in 1986, which although it demonstrated intake below the $2 \mathrm{~g}$ limit, also demonstrated that intake in urban areas was almost double that of rural areas (0.86 g vs $1.65 \mathrm{~g}) .{ }^{21}$ Globally, 1.7 million CVD deaths each year are estimated to be due to excess sodium intake. ${ }^{1}$

Multiple meta-analyses have demonstrated the correlation between low fruit and vegetable intake and an increase in both all-cause and cardiovascular mortality, often attributed to the deficiency in protective compounds contained in them including vitamin $\mathrm{C}$ and flavonoids, which may help to reduce oxidant vascular damage. The paucity of data on 


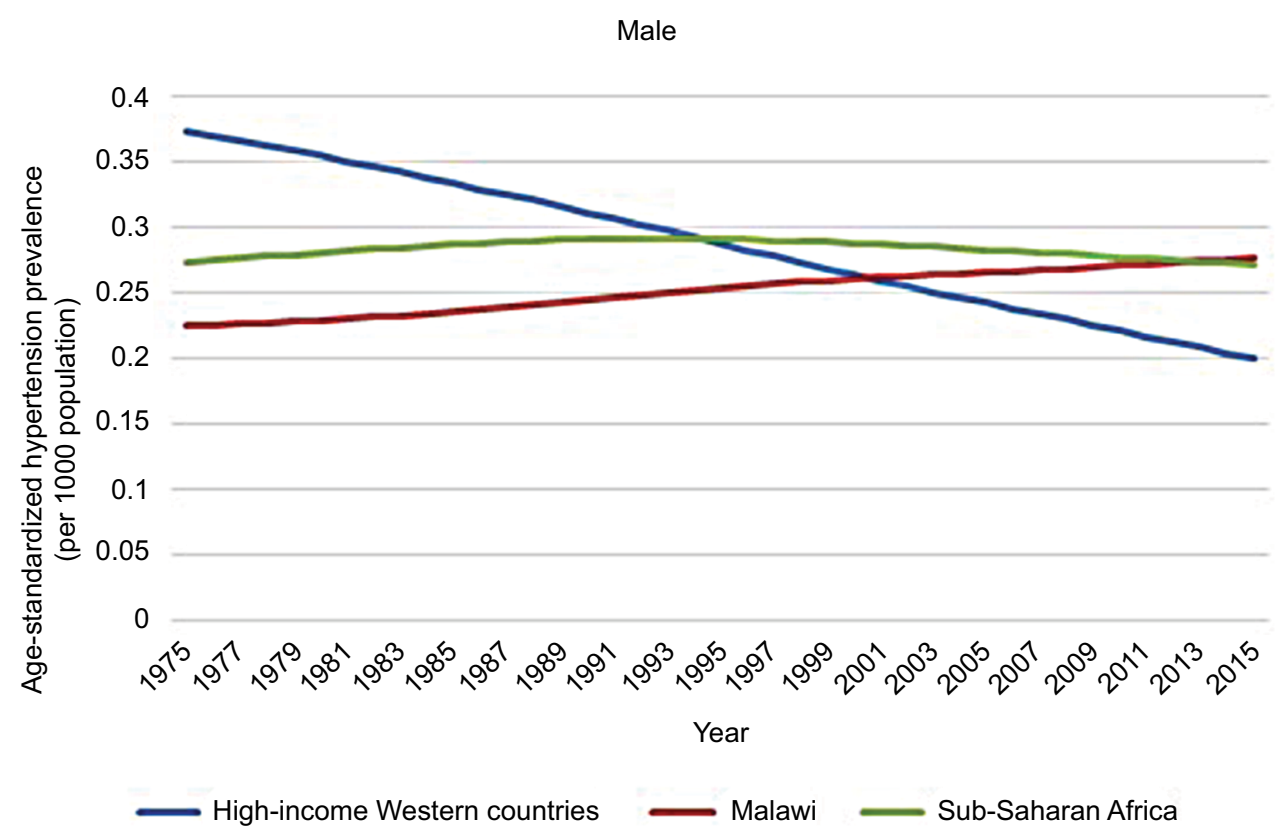

Female

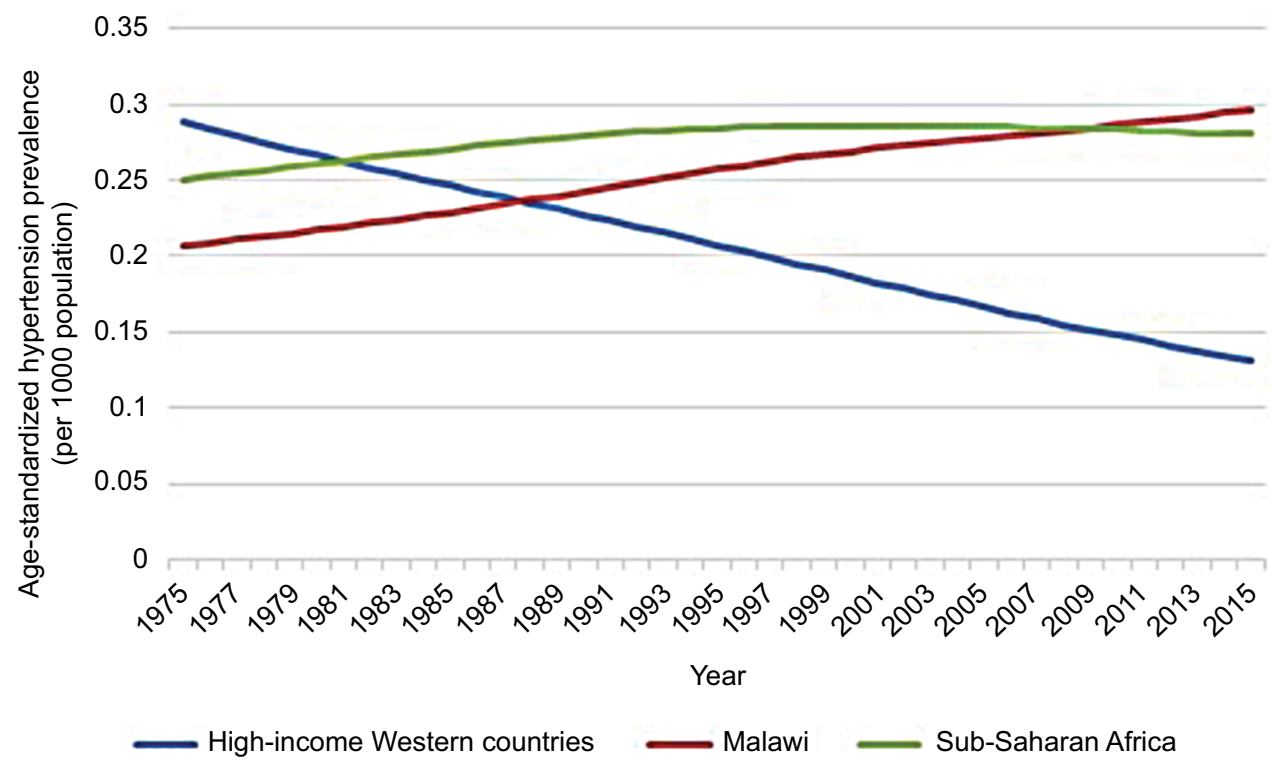

Figure I Age-standardized hypertension prevalence in SSA, Malawi and high-income Western countries 1975-2015, according to data from the NCD Risk Factor Collaboration.

Note: Data from NCD Risk Factor Collaboration (NCD-RisC). Data Downloads: Diabetes. Available from: http://ncdrisc.org/data-downloads-diabetes.html. Accessed June $14,2018.12$

Abbreviation: SSA, Sub-Saharan Africa.

this subject in Africa is evident and no meta-analyses on this subject include studies from the region. ${ }^{22,23}$

Obesity can be regarded as a disorder of chronic inflammation and is likely to contribute to CVD by additional mechanisms independent of its contribution to a state of insulin resistance (explained in the following text). ${ }^{24}$

\section{Chronic respiratory diseases}

CRD include chronic obstructive pulmonary disease (COPD), asthma, and occupational lung diseases. Although endemic in Malawi, these diseases are often overlooked, and data are scarce due to much of the focus being on the much larger burden of communicable lung diseases such as TB, childhood 
pneumonia, and HIV-related lung diseases such as pneumocystis pneumonia. ${ }^{25}$

Malawi has a low prevalence of asthma of approximately $5 \%$, especially when compared to the UK, which has one of the world's highest prevalence rates of $>12 \% .{ }^{26,27}$ Despite this, it is likely that asthma remains underdiagnosed and undertreated in Malawi, evidenced by an asthma age-standardized mortality rate higher than that of the UK. As well as this, the ISAAC study series has shown a trend of increasing incidence across the African region indicating that the epidemiological transition may be accompanied by a commensurate rise in asthma rates consistent with the "hygiene hypothesis" of asthma pathogenesis. $^{28}$

Smoking epidemiology is described previously; more men and fewer women smoke in Malawi than the average number in low-income countries. ${ }^{29}$ The major obstacles that Malawi faces in combating smoking rates and related mortality are related to being one of the most tobacco-dependent economies in the world, with little regulation on the sale and advertisement of tobacco products. An economy so dependent on an industry with a combined revenue far in excess of Malawi's GDP weakens the ability to legislate to enforce effective public health policies against tobacco consumption. ${ }^{30,31}$ The financial and political pressure exerted by the tobacco industry has been highlighted in recent years by high-profile cases like the 2010 legal case "Phillip Morris vs Uruguay" where a large tobacco multinational company attempted to sue a country for brand devaluation due to the introduction of anti-smoking legislation. ${ }^{32}$ Recent reports have revealed court cases against African countries by multinational companies including Uganda, Kenya, and the Democratic Republic of Congo. ${ }^{33}$

Asthma allergens and risk factors implicated in asthma differ from those established in North-America and Europe, though mostly due to differences in occupational exposures and local fauna rather than differing pathogenesis. ${ }^{34}$ Some studies have suggested that infections with helminths such as Schistosoma, which is found in abundance in Lake Malawi, may attenuate the atopic response to allergens. A study in Gabonese children found that those with urinary schistosomiasis reacted to dust-mite allergen skin prick less frequently than those without. ${ }^{35}$

Occupational lung disease in Malawi is not well researched but certain workers are recognized to be at risk, namely those in the textiles, wood-cutting, tea and coffee processing, and tobacco industries. ${ }^{24}$ Malawi is one of the top 10 exporters of tobacco worldwide and there is likely to be an underappreciated burden of occupational disease associated with its production. "Tobacco Worker's Lung" is an extrinsic allergic alveolitis in response to the Aspergillus fungus that is often found in fields and factories; there are no data on the incidence in Malawi. ${ }^{36}$

Ambient air pollution is recognized as a global risk factor for respiratory disease and is emerging as a previously underappreciated risk factor for CVD. Two industrializing African urban centers, Kaduna (Nigeria) and Kampala (Uganda), were highlighted in a recent study where harm from inhaled particulate matter was estimated to negate the health benefits of cycling after 105 and 90 minutes, respectively. The high levels of particulate matter in these cases are usually attributable to unregulated industrial emissions, low-quality fuel combustion, and the burning of waste material for disposal. ${ }^{37}$ Levels of such particulate matter are low in Malawi with its small industrial sector, reliance on renewable energy (95\% of national grid electricity coming from a hydroelectric source), and $85 \%$ of the population living in rural areas. However, the population may instead be at increased risk from high levels of "indoor" air pollution.

Only $9 \%$ of the Malawian population is connected to the power grid, with this minority also experiencing regular power cuts. This means $95 \%$ of people rely on burning wood or other plant materials as their main source of domestic energy. In a 2008 study of 62 Malawian homes, $100 \%$ had fine particulate matter levels that exceeded WHO limits for outdoor air. ${ }^{38}$ Although no studies exist in Malawi, biomass fuel use is an established risk factor for the development of COPD and may in fact be the most important risk factor worldwide..$^{39,40}$ Indoor pollution in Malawi may be a more significant problem in females, especially due to the cultural practice of spending more time cooking with biomass in poorly ventilated homes. This may explain a Ugandan study that described similar COPD prevalence in both sexes despite more than double the proportion of women with COPD being never smokers (74\% vs $31 \%) .{ }^{41}$ It has been suggested that biomass-related COPD represents a separate disease phenotype with a younger age of onset (earlier exposure), more frequent symptomatic wheeze, and less parenchymal damage. ${ }^{42}$

\section{Cancer}

The large burden of infectious disease has a significant effect on the epidemiology of cancer in Malawi. Worldwide, cancer is predominantly a disease of later life; with life expectancy in Malawi averaging 59 years for males and 60 years for females, a low incidence of cancer could be expected. However, for some types of cancer Malawi has some of the highest incidence rates in the world. ${ }^{2,43}$ 
Infectious agents have a role in the pathogenesis of many cancers in Malawi, and the endemic nature of these infections, in addition to a high number of immunocompromised individuals due to coexisting HIV infection ( 1 in 10 people), is likely to contribute to these high rates. ${ }^{44}$ Cancer surgery with curative intent is very limited in Malawi, and management of most solid tumors is palliative. ${ }^{43}$

Overall, the age-standardized incidence rates for all cancers in Malawi is 156 cases per 100,000, which although higher than the average for SSA of 121 is still much lower than the rates in high-income Western countries, the EU average standing at 278 and the USA at $318 .{ }^{45}$

Esophageal cancer incidence rates in Malawi are the highest in the world at 24.2 cases per 100,000 with no single identifiable causative risk factor. The current consensus is that the excess risk is multifactorial and may be a combination of high levels of aflatoxin in the diet (a mycotoxin found in improperly stored maize, the staple crop in Malawi), high strength alcohol consumption and tobacco consumption. ${ }^{46}$ There has been specific interest in the homebrewed maize spirit known as Kachasu due to its high alcohol percentage (up to $70 \%$ ) and high levels of nitrosamines and contaminants such as zinc. ${ }^{47}$

There is an indication that HIV infection may have a role in esophageal carcinogenesis, with 1 study noting that esophageal cancer rates have paralleled those of Kaposi's sarcoma. ${ }^{46}$

Kaposi's sarcoma is the most common cancer in Malawi, constituting over $50 \%$ of all cancer diagnoses. The pathogenesis of Kaposi's sarcoma is related to infection with human herpesvirus-8 in HIV-positive patients with low CD4 counts. ${ }^{46}$

Bladder cancer mortality rates in Malawi are the 3rd highest in Africa. As previously mentioned, infection with the helminths Schistosoma haematobium and Schistosoma mansoni is common in Malawi, with a systematic review finding reports of prevalence in some areas as high as $94.9 \%$ and $67.0 \%$, respectively. ${ }^{48}$ Schistosomal infection of the bladder is a recognized risk factor for the development of squamous cell carcinoma of the bladder (SCC) with egg deposition in the bladder wall causing local inflammation and enabling some schistosomal antigens to inhibit host cell apoptosis. Unlike the predominantly transitional cell tumors seen in developed countries, schistosomal-associated SCC is usually well differentiated and only locally invasive. ${ }^{49}$ Despite this, late presentation and few facilities for resection mean that mortality in Malawi remains high. ${ }^{50}$

Cervical cancer incidence and mortality in Malawi are the highest in the world and it is the most commonly diagnosed cancer in Malawian females at 75.9 cases per 100,000. This is attributed to the high prevalence of human papillomavirus (HPV) infection, which is known to lead to dyskaryosis and malignant change of the cervical epithelium. ${ }^{50,51} \mathrm{HPV}$ and HIV are both thought to predispose to infection with each other, and HIV co-infection is believed to accelerate the rate of malignant transformation in those with HPV-related dyskaryosis; the high levels of both viruses in the population act synergistically to produce the high incidence rates of cervical cancer. ${ }^{52}$

In Malawi, non-Hodgkin's lymphoma (NHL) is the third most commonly diagnosed cancer. These are predominantly cases of Burkitt lymphoma (BL), a B-cell lymphoma that is characterized by a range of chromosomal translocations and genetic mutations; particularly of the $c$-myc oncogene..$^{43,53}$ Epstein-Barr virus (EBV) is believed to have a role in the deregulation of this oncogene as well as promoting the survival of malignant cells. Epidemiological clustering of both diseases suggests an association between BL and Plasmodium falciparum infection, though a definitive role and interaction with EBV has not been established. ${ }^{54}$ Certain plant toxins such as those from the Euphorbiaceae family have been suggested as co-factors in BL development and have been shown to induce EBV-associated chromosomal abnormalities in vitro. A 1993 case-control study from Malawi reported that people with BL were significantly more likely to have Euphorbiaceae plants at their homes. ${ }^{55}$ The occurrence rate of BL is also increased in people with concurrent HIV infection, which increases the occurrence of all types of NHL by a factor of 60-200.56

\section{Diabetes}

Diabetes prevalence is increasing throughout SSA, with the age-standardized prevalence rates for men in Malawi and SSA approaching those rates in high-income Western countries and rates in women surpassing them (Figure 2). Much of this increase is due to the rise in type 2 diabetes, although epidemiological studies do not differentiate between type 1 and $2 .{ }^{57}$ The paucity of data from throughout the African region means that prevalence and trends are based on estimation calculations using low-quality epidemiological studies; in a Lancet worldwide diabetes study " 21 (39\%) of the 54 countries without data were in sub-Saharan Africa". ${ }^{58}$ Estimates of prevalence in Malawi range from 2.3\% (updated figures seen when URL was updated) (IDF) to 5.7\% (2009 STEPS Survey), the latter approaching the prevalence in the UK (6\%) despite having less than half of the percentage of people classed as overweight or obese ( $21.9 \%$ vs $62.9 \%$ ). ${ }^{6,959}$

The dominant theory of diabetes risk is one of "lifestyle factors" whereby an increasingly sedentary lifestyle with 
Male

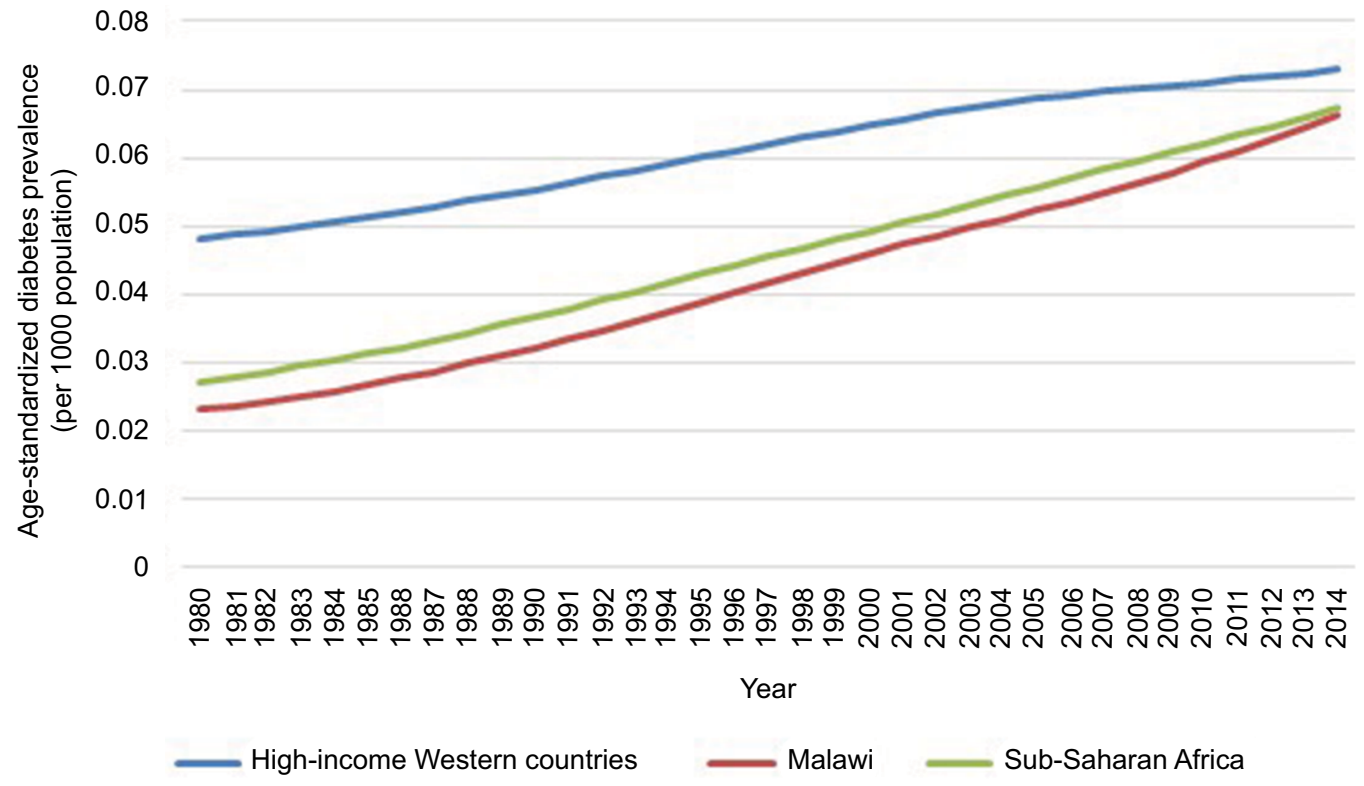

Female

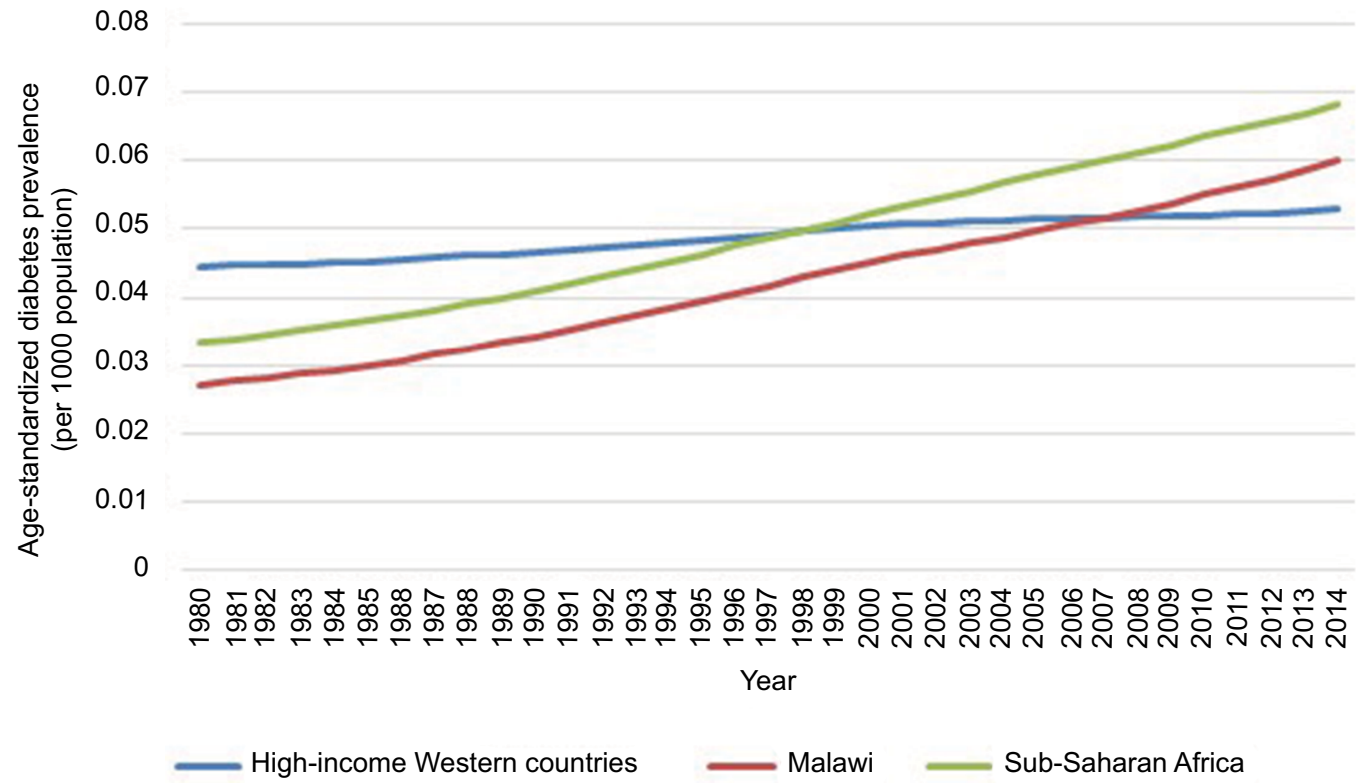

Figure 2 Age-standardized diabetes prevalence in SSA, Malawi and high-income Western countries 1980-2014, according to data from the NCD Risk Factor Collaboration. Note: NCD Risk Factor Collaboration (NCD-RisC). Data Downloads: Blood Pressure. Available from: http://ncdrisc.org/data-downloads-blood-pressure.html. Accessed June $14,2018^{58}$

Abbreviation: SSA, Sub-Saharan Africa.

concurrent calorie excess predisposes to the development of the "metabolic syndrome". Diabetes epidemiology in SSA shows a 2-5 times increased risk for diabetes or impaired fasting glucose in urban areas, which are more associated with these lifestyle risk factors. ${ }^{60}$ With rural to urban migration forming part of the wider epidemiological transition across the region (SSA has the fastest urbanization rate in the world), this trend is likely to continue. ${ }^{61}$

\section{Adiposity}

In keeping with worldwide trends, studies across Africa show a significant positive correlation between increased body mass 
index (BMI) and diabetes risk. ${ }^{62}$ More than 1 in 5 Malawians are overweight or obese, with the rate in females significantly greater than in males $(28.1 \%$ vs $16.1 \%) .{ }^{9}$ Debate remains over the best measure of adiposity in African populations due to a lack of data. Some studies have suggested that African populations may have a lower percentage body fat than Europid populations at the same BMI, although epidemiological data for the SSA regions indicated that they may develop diabetes at lower BMIs on average. ${ }^{63,64}$ Roles for other measurements like waist circumference (WC) and waist hip ratio (WHR) have not been established but in a small study in northern Malawi, WHR was found to have a greater sensitivity to detect diabetes patients than BMI and WC when using WHO-recommended cutoffs. ${ }^{65}$ It appears that the central distribution of this more hormonally active fat is important, with 1 study including Afro-Caribbean participants finding that WC was associated with metabolic syndrome clustering, independent of BMI. ${ }^{66}$

\section{Physical activity}

Growing service sector industries and changing leisure activities across SSA mean people are engaging in less physical activity. Job transition from agricultural to service sectors typically is associated with a decrease in physical activity, and recreational exercise is a culturally uncommon pastime, perhaps due to the historically strenuous nature of subsistence farming. ${ }^{67}$ One Cameroonian study reported significantly decreased energy expenditure in urban dwellers compared to rural dwellers as well as a significantly increased rate of diabetes. Urban dwellers recorded shorter walking and cycling times per week and "lighter intensity" occupations. ${ }^{68}$ The trend of decreasing physical activity as SSA undergoes further economic development will likely worsen the "energy imbalance" associated with the obesity epidemic whilst also increasing diabetes risk by mechanisms independent of weight gain. A number of prospective and cross-sectional studies have shown even moderate exercise to reduce the risk of developing diabetes across numerous ethnic groups, believed to be due to exercise-induced augmentation of insulin action. ${ }^{69}$

\section{Diet}

Aside from calorie excess, additional dietary factors have been associated with diabetes risk and are prevalent in Malawi. Data from the Nurses' Health Study showed that participants with a diet of high glycemic load or glycemic index in addition to low cereal fiber intake had an approximately $50 \%$ increased risk of developing diabetes. ${ }^{70}$ In Malawi, the staple carbohydrate dish Nsima is made from ground maize (cornmeal) and water; it has both a high glycemic index (94.06 in 1 study) and low cereal fiber content. Nsima can be made from flour of various particle sizes according to grinding. Smaller particle flour increases the glycemic index of the meal and the ability to adjust the level of grinding, and therefore adjustment of the glycemic profile of the meal presents an opportunity to reduce dietary risk with simple changes to food preparation. ${ }^{71}$

Fiber and antioxidant (especially vitamin C) intake from fruit and vegetables has shown associations with decreased diabetes risk in observational studies but the exact significance is unclear. In the Malawi STEPS survey, fruit and vegetable intake was low with $97.5 \%$ of people eating fewer than 5 servings of fruit and vegetables per day, the average being 2.1 servings a day. ${ }^{9}$

Sugar sweetened beverages (SSBs) or "soft drinks" are widely consumed in Malawi and are available for lower prices than bottled water at many retailers. ${ }^{72}$ Consumption is increasing - especially in young people, with 1 study of Malawian schoolchildren reporting that 50 out of $60(83.3 \%)$ were consuming SSBs at least once a day. ${ }^{73} \mathrm{~A}$ meta-analysis of 11 studies showed that people consuming this level of SSB had a $26 \%$ greater risk of developing metabolic syndrome or diabetes than those consuming $<1$ a month, proposed to be the effect of the added dietary glycemic load. ${ }^{74}$

\section{latrogenic causes}

Hypertension in Malawi is most often managed using thiazide diuretics due to their low cost and widespread availability. Insulin resistance and hyperglycemia are recognized side effects of thiazide medications and widespread use may be contributing to diabetes risk. ${ }^{75,76}$

\section{Relationship between communicable and non-communicable diseases}

As is clear in the case of cancer, often a distinction between communicable diseases and NCDs is not possible - especially in a population where HIV is endemic. HIV is increasingly recognized as a risk factor for CVD, with a meta-analysis of 20 studies reporting the relative risk of CVD, in HIV-infected patients compared to uninfected patients, to be 1.61. Antiretroviral drugs used to treat HIV can cause hypertriglyceridemia, hypercholesterolemia, and hyperglycemia; in the same study, the relative risk for HIV patients taking ART treatment was higher at 2.00. ${ }^{77}$ The hyperglycemia side effect - especially from protease inhibitors - may also contribute to diabetes risk. Reciprocally, NCDs may increase the burden of communicable disease, for example diabetes patients are over 3 times more likely to become infected with TB. These findings are the basis of the bidirectional screening programs that are being established in some low-middle income countries. ${ }^{78,79}$ 


\section{Where is intervention most needed?}

Early intervention in Malawi's NCD epidemic may be more effective in reducing risk behaviors and adjusting how health care infrastructure is developed. For example, taxation to deter the purchase of calorie dense convenience foods and SSBs is likely to be more politically acceptable and effective if introduced before consumption becomes more widespread. ${ }^{80}$

Two important primary steps to address NCD rates in Malawi would be to gather more epidemiological data, especially regarding prevalence, and establish a health promotion strategy to raise awareness about the most common NCDs, to health care providers and the public. Electronic registries to collect data on NCDs would be relatively simple to set up with the ability to attach additional modules to existing systems already used to manage and monitor HIV patients. ${ }^{65}$

A campaign of health promotion is essential to help control rates of all NCDs in Malawi, from CVD where almost all dietary sodium is added during the cooking process, to respiratory disease and cancer where the health implications of tobacco are poorly publicized, especially on packaging. ${ }^{21,29}$ Promoting better ventilation whilst using wood burning stoves inside the home, such as using the stove in doorways or next to windows, is a simple way to help reduce the exposure to indoor air pollution.

Health promotion strategies for the public can be modeled on those currently used for HIV where print materials, television broadcasts, and public billboards have all been utilized to good effect. ${ }^{81}$ SMS-based health promotion is also emerging as an effective way to deliver health education in an inexpensive and widespread manner as mobile phone ownership continues to increase rapidly across SSA. ${ }^{82}$

In the case of diabetes and CVD, cultural beliefs regarding what constitutes a health body weight may be contributing toward rising obesity rates. In a small outpatient survey of 40 patients in northern Malawi, 57.4\% of respondents selected a BMI of $40 \mathrm{~kg} / \mathrm{m}^{2}$ as the "healthiest body weight" when presented with 5 images corresponding to BMIs ranging from 18 to $40 \mathrm{~kg} / \mathrm{m}^{2}{ }^{65}$ The reasons for this are complex; it is a combination of the cultural perceptions of body image in addition to obesity reflecting wealth and status and weight loss being associated with the wasting from AIDS and malnutrition. In this instance, educational initiatives targeted at schoolchildren and already effectively employed in HIV education can begin to challenge these beliefs about body weight. National standards could be set for school curricula to focus on dietary education, for example teaching portion control by using tangible measurements like a fist. There could also be a greater emphasis on structured recreational sports to help make exercise a more normal part of daily life from an early age. Governmental funding for such schemes is low, and these public health campaigns are usually provided by non-governmental organizations and charities. Although taking on an additional educational initiative could be an overwhelming workload, the current HIV campaign is becoming increasingly self-sufficient within the involved schools and it is important to utilize the existing infrastructure to promote awareness of other diseases.

\section{Conclusion}

In Malawi and across SSA, the incidence and mortality of NCDs are rising. The paucity of data regarding NCD risk factors in the region severely affects the ability to interpret disease trends and plan population specific interventions, and more high-quality epidemiological data are essential. As public health interventions are ultimately data driven, carrying out such surveys is fundamental to motivating change.

However, what is clear is that a comprehensive campaign of health promotion is required to begin to address the development of risk behaviors - especially those associated with an increasingly sedentary, calorie-rich, and "Westernized" urban lifestyle - that are contributing to a rapidly increasing burden of NCD throughout LMIs.

\section{Acknowledgments}

The authors are grateful to the Wellcome Trust ISSF at Imperial College London for funding support and to the United Kingdom National Institute for Health Research Biomedical Facility at Imperial College London for infrastructure support. All the authors acknowledge the support of Mzuzu Central Hospital and Luke International Norway for research support in Malawi.

\section{Disclosure}

The authors report no conflicts of interest in this work.

\section{References}

1. WHO. Global Action Plan for the Prevention and Control of Noncommunicable Diseases 2013-2020. 2013. Available from: http://www.who. int/nmh/publications/ncd_action_plan/en/. Accessed April 1, 2017.

2. Central Intelligence Agency. The World Factbook 2016: Malawi. Available from: https:/www.cia.gov/library/publications/the-world-factbook/ geos/mi.html. Accessed April 1, 2017.

3. WHO. Noncommunicable Diseases (NCD) Country Profiles: Malawi. 2014. Available from: http://www.who.int/nmh/countries/mwi_en.pdf. Accessed April 1, 2017.

4. Institute for Health Metrics and Evaluation. Countries profiles-Malawi. Available from http://www.healthdata.org/malawi. Accessed May 30, 2018 . 
5. Roth GA, Huffman MD, Moran AE, et al. Global and regional patterns in cardiovascular mortality from 1990 to 2013. Circulation. 2015;132(17):1667-1678.

6. Public Health England. About obesity; 2017. Available from: http:// webarchive.nationalarchives.gov.uk/20170110165525/https://www. noo.org.uk/NOO_about_obesity. Accessed April 1, 2017.

7. British Heart Foundation. Cardiovascular disease statistics 2014. Available from: https://www.bhf.org.uk/publications/statistics/cardiovascular-disease-statistics-2014. Accessed April 1, 2017.

8. Office for National Statistics. Adult smoking habits in the UK: 2016. Available from: https://www.ons.gov.uk/peoplepopulationandcommunity/healthandsocialcare/healthandlifeexpectancies/bulletins/ adultsmokinghabitsingreatbritain/2016. Accessed April 1, 2017.

9. WHO. Malawi National STEPS Survey for Chronic Non-Communicable Diseases and their Risk Factors. 2010. Available from. http://www. who.int/ncds/surveillance/steps/Malawi_2009_STEPS_Report.pdf. Accessed May 30, 2018.

10. Lindhorst J, Alexander N, Blignaut J, Rayner B. Differences in hypertension between blacks and whites: an overview. Cardiovasc J Afr. 2007;18(4):241-247.

11. Opie LH, Seedat YK. Hypertension in sub-Saharan African populations. Circulation. 2005;112(23):3562-3568.

12. NCD Risk Factor Collaboration (NCD-RisC). Data Downloads: Diabetes. Available from: http://ncdrisc.org/data-downloads-diabetes.html. Accessed June 14, 2018.

13. O’Donnell MJ, Xavier D, Liu L, et al; INTERSTROKE investigators. Risk factors for ischaemic and intracerebral haemorrhagic stroke in 22 countries (the INTERSTROKE study): a case-control study. Lancet 2010;376(9735):112-123.

14. Soliman EZ, Juma H. Cardiac disease patterns in northern Malawi: epidemiologic transition perspective. J Epidemiol. 2008;18(5):204-208.

15. Centers for Disease Control and Prevention. Global Health - Malawi. Available from: https://www.cdc.gov/globalhealth/countries/malawi/. Accessed April 1, 2017.

16. Sliwa K, Wilkinson D, Hansen C, et al. Spectrum of heart disease and risk factors in a black urban population in South Africa (the Heart of Soweto Study): a cohort study. Lancet. 2008;371(9616):915-922.

17. Edwards R, Unwin N, Mugusi F, et al. Hypertension prevalence and care in an urban and rural area of Tanzania. J Hypertens. 2000;18(2):145-152.

18. Pampel F. Tobacco use in sub-Sahara Africa: estimates from the demographic health surveys. Soc Sci Med. 2008;66(8):1772-1783.

19. Strazzullo P, D’Elia L, Kandala NB, Cappuccio FP. Salt intake, stroke, and cardiovascular disease: meta-analysis of prospective studies. BMJ. 2009;339:b4567.

20. Reddy KS, Yusuf S. Emerging epidemic of cardiovascular disease in developing countries. Circulation. 1998;97(6):596-601.

21. Oyebode O, Oti S, Chen YF, Lilford RJ. Salt intakes in sub-Saharan Africa: a systematic review and meta-regression. Popul Health Metr. 2016;14:1.

22. Dauchet L, Amouyel P, Hercberg S, Dallongeville J. Fruit and vegetable consumption and risk of coronary heart disease: a meta-analysis of cohort studies. J Nutr. 2006;136(10):2588-2593.

23. Wang X, Ouyang Y, Liu J, et al. Fruit and vegetable consumption and mortality from all causes, cardiovascular disease, and cancer: systematic review and dose-response meta-analysis of prospective cohort studies. BMJ. 2014;349:g4490.

24. Poirier P, Giles TD, Bray GA, et al. Obesity and cardiovascular disease: pathophysiology, evaluation, and effect of weight loss. Arterioscler Thromb Vasc Biol. 2006;26(5):968-976.

25. Gordon S, Graham S. Epidemiology of respiratory disease in Malawi. Malawi Med J. 2006;18(3):134-146.

26. WHO. Analytical summary - non-communicable diseases and conditions 2016. Available from: http://www.aho.afro.who.int/profiles_information/index.php/Malawi:Analytical_summary_-_Noncommunicable_diseases_and_conditions. Accessed April 1, 2017.
27. British Lung Foundation. Asthma statistics 2017. Available from: https:// statistics.blf.org.uk/asthma. Accessed April 1, 2017.

28. Mallol J, Crane J, von Mutius E, Odhiambo J, Keil U, Stewart A; ISAAC Phase Three Study Group. The International Study of Asthma and Allergies in Childhood (ISAAC) Phase Three: a global synthesis. Allergol Immunopathol (Madr). 2013;41(2):73-85.

29. Eriksen M, Mackay J, Schluger N, Gomeshtapeh F, Drope J. The Tobacco Atlas, 5th. Atlanta, GA: American Cancer Society; 2015. Available from: http://www.tobaccoatlas.org/country-data/malawi/. Accessed April 1, 2017.

30. $\mathrm{Hu} \mathrm{TW}$, Lee AH. Tobacco control and tobacco farming in African Countries. J Public Health Policy. 2015;36(1):41-51.

31. Saloojee Y, Dagli E. Tobacco industry tactics for resisting public policy on health. Bull World Health Organ. 2000;78(7):902-910.

32. Boseley S. Threats, bullying, lawsuits: tobacco industry's dirty war for the African market. The Guardian. 2017. Available from: https:// www.theguardian.com/world/2017/jul/12/big-tobacco-dirty-war-africamarket. Accessed November 1, 2017.

33. Crosbie E, Sosa P, Glantz SA. Defending strong tobacco packaging and labelling regulations in Uruguay: transnational tobacco control network versus Philip Morris International. Tob Control. 2018;27(2):185-194.

34. Wjst M, Boakye D. Asthma in Africa. PLoS Med. 2007;4(2):e72.

35. van den Biggelaar AH, van Ree R, Rodrigues LC, et al. Decreased atopy in children infected with Schistosoma haematobium: a role for parasite-induced interleukin-10. Lancet. 2000;356(9243):1723-1727.

36. Ismail T, McSharry C, Boyd G. Extrinsic allergic alveolitis. Respirology. 2006;11(3):262-268.

37. Tainio M, de Nazelle AJ, Gotschi T, et al. Can air pollution negate the health benefits of cycling and walking? Prev Med. 2016;87:233-236.

38. Fullerton DG, Semple S, Kalambo F, et al. Biomass fuel use and indoor air pollution in homes in Malawi. Occup Environ Med. 2009;66(11):777-783.

39. Salvi S, Barnes PJ. Is exposure to biomass smoke the biggest risk factor for COPD globally? Chest. 2010;138(1):3-6.

40. Hu G, Zhou Y, Tian J, et al. Risk of COPD from exposure to biomass smoke: a metaanalysis. Chest. 2010;138(1):20-31.

41. van Gemert F, Kirenga B, Chavannes N, et al. Prevalence of chronic obstructive pulmonary disease and associated risk factors in Uganda (FRESH AIR Uganda): a prospective cross-sectional observational study. Lancet Glob Health. 2015;3(1):e44-e51.

42. Salvi S. The silent epidemic of COPD in Africa. Lancet Glob Health. 2015;3(1):e6-e7.

43 Msyamboza KP, Dzamalala C, Mdokwe C, et al. Burden of cancer in Malawi; common types, incidence and trends: national population-based cancer registry. BMC Res Notes. 2012;5:149.

44. National Statistical Office of Malawi. Malawi Demographic and Health Survey 2010. Available from: https://dhsprogram.com/pubs/pdf/FR247/ FR247.pdf. Accessed April 1, 2017.

45. Ferlay J, Soerjomataram I, Ervik M, et al. GLOBOCAN 2012 v1.0, Cancer Incidence and Mortality Worldwide: IARC CancerBase No. 11. Lyon, France: International Agency for Research on Cancer; 2013. Available from: http://globocan.iarc.fr. Accessed April 1, 2017.

46. Mlombe Y, Dzamalala C, Chisi J, Othieno-Abinya N. Oesophageal cancer and Kaposi's Sarcoma in Malawi: a comparative analysis. Malawi Med J. 2009;21(2):66-68.

47. McGlashan ND. Oesophageal cancer and alcoholic spirits in central Africa. Gut. 1969;10(8):643-650.

48. Makaula P, Sadalaki JR, Muula AS, Kayuni S, Jemu S, Bloch P. Schistosomiasis in Malawi: a systematic review. Parasit Vectors. 2014;7:570

49. Zaghloul MS. Bladder cancer and schistosomiasis. J Egypt Natl Cancer Inst. 2012;24(4):151-159.

50. Msyamboza KP, Manda G, Tembo B, et al. Cancer survival in Malawi: a retrospective cohort study. Pan Afr Med J. 2014;19:234.

51. Msyamboza KP, Phiri T, Sichali W, Kwenda W, Kachale F. Cervical cancer screening uptake and challenges in Malawi from 2011 to 2015: retrospective cohort study. BMC Public Health. 2016;16(1):806. 
52. Ferenczy A, Coutlée F, Franco E, Hankins C. Human papillomavirus and HIV coinfection and the risk of neoplasias of the lower genital tract: a review of recent developments. CMAJ. 2003;169(5):431-434.

53. Orem J, Mbidde EK, Lambert B, de Sanjose S, Weiderpass E. Burkitt's lymphoma in Africa, a review of the epidemiology and etiology. Afr Health Sci. 2007;7(3):166-175.

54. Mutalima N, Molyneux E, Jaffe H, et al. Associations between Burkitt lymphoma among children in Malawi and infection with HIV, EBV and malaria: results from a case-control study. PLoS One. 2008;3(6):e2505.

55. van den Bosch C, Griffin BE, Kazembe P, Dziweni C, Kadzamira L. Are plant factors a missing link in the evolution of endemic Burkitt's lymphoma? Br J Cancer. 1993;68(6):1232-1235.

56. Grogg KL, Miller RF, Dogan A. HIV infection and lymphoma. J Clin Pathol. 2007;60(12):1365-1372.

57. WHO. Global Report on Diabetes. 2016. Available from http://www. who.int/diabetes/global-report/en/. Accessed May 30, 2018.

58. NCD Risk Factor Collaboration (NCD-RisC). Data Downloads: Blood Pressure. Available from: http://ncdrisc.org/data-downloads-bloodpressure.html. Accessed June 14, 2018.

59. International Diabetes Federation. IDF Diabetes Atlas. 8th edition. Brussels, Belgium: International Diabetes Federation, 2017. Available from http://www.diabetesatlas.org. Accessed May 30, 2018.

60. Mbanya JC, Ramiaya K. Diabetes mellitus. In: Jamison DT, Feachem RG, Makgoba MW, et al., editors. Disease and Mortality in Sub-Saharan Africa. 2nd ed. Washington, DC: The International Bank for Reconstruction and Development/ The World Bank; 2006. Chapter 19. Available from: https:// www.ncbi.nlm.nih.gov/books/NBK2291/. Accessed April 1, 2017.

61. Mbanya JC, Motala AA, Sobngwi E, Assah FK, Enoru ST. Diabetes in sub-Saharan Africa. Lancet. 2010;375(9733):2254-2266.

62. Mbanya JC, Assah FK, Saji J, Atanga EN. Obesity and type 2 diabetes in Sub-Sahara Africa. Curr Diab Rep. 2014;14(7):501.

63. Frank LK, Heraclides A, Danquah I, Bedu-Addo G, Mockenhaupt FP, Schulze MB. Measures of general and central obesity and risk of type 2 diabetes in a Ghanaian population. Trop Med Int Health. 2013;18(2):141-151.

64. Gaillard T. Consequences of abdominal adiposity within the metabolic syndrome paradigm in black people of African ancestry. J Clin Med. 2014;3(3):897-912.

65. Gowshall M. A Registry-Based Approach to Diabetes Risk Scores in Malawi [dissertation]. London: Imperial College London; 2016.

66. Okosun IS, Liao Y, Rotimi CN, Prewitt TE, Cooper RS. Abdominal adiposity and clustering of multiple metabolic syndrome in White, Black and Hispanic Americans. Ann Epidemiol. 2000;10(5):263-270.

67. Jasper US. Diabetes and exercise in sub-Saharan Africa: challenges and way forward. Int J Diabetes Metabol. 2014;5(4):1-3.

68. Sobngwi E, Mbanya JC, Unwin NC, et al. Physical activity and its relationship with obesity, hypertension and diabetes in urban and rural Cameroon. Int J Obes Relat Metab Disord. 2002;26(7):1009-1016.
69. Colberg SR, Sigal RJ, Fernhall B, et al; American College of Sports Medicine; American Diabetes Association. Exercise and type 2 diabetes: the American College of Sports Medicine and the American Diabetes Association: joint position statement. Diabetes Care. 2010;33(12):e147-e167.

70. Ardisson Korat AV, Willett WC, Hu FB. Diet, lifestyle, and genetic risk factors for type 2 diabetes: a review from the Nurses' Health Study, Nurses' Health Study 2, and Health Professionals' Follow-up Study. Curr Nutr Rep. 2014;3(4):345-354

71. Mlotha V, Mwangwela AM, Kasapila W, Siyame EW, Masamba K. Glycemic responses to maize flour stiff porridges prepared using local recipes in Malawi. Food Sci Nutr. 2015;4(2):322-328.

72. Singh GM, Micha R, Khatibzadeh S, et al; Global Burden of Diseases Nutrition and Chronic Diseases Expert Group (NutriCoDE). Global, Regional, and National Consumption of Sugar-Sweetened Beverages, Fruit Juices, and Milk: a systematic assessment of beverage intake in 187 countries. PLoS One. 2015;10(8):e0124845.

73. Kalimbira A, Gondwe E. Consumption of sweetened beverages among school-going children in a densely populated township in Lilongwe, Malawi. Malawi Med J. 2015;27(2):55-59.

74. Malik VS, Popkin BM, Bray GA, Despres JP, Willett WC, Hu FB. Sugar-sweetened beverages and risk of metabolic syndrome and type 2 diabetes: a meta-analysis. Diabetes Care. 2010;33(11): 2477-2483.

75. Msyamboza KP, Kathyola D, Dzowela T, Bowie C. The burden of hypertension and its risk factors in Malawi: nationwide populationbased STEPS survey. Int Health. 2012;4(4):246-252.

76. Carter BL, Ernst ME. Thiazide-induced hyperglycemia: can it be prevented? Am J Hypertens. 2009;22(5):473.

77. Islam FM, Wu J, Jansson J, Wilson DP. Relative risk of cardiovascular disease among people living with HIV: a systematic review and metaanalysis. HIV Med. 2012;13(8):453-468.

78. Harries AD, Kumar AM, Satyanarayana S, et al. Addressing diabetes mellitus as part of the strategy for ending TB. Trans $R$ Soc Trop Med Hyg. 2016;110(3):173-179.

79. Dooley KE, Chaisson RE. Tuberculosis and diabetes mellitus: convergence of two epidemics. Lancet Infect Dis. 2009;9(12):737-746.

80. Manyema M, Veerman JL, Chola L, Tugendhaft A, Labadarios D, Hofman K. Decreasing the burden of type 2 diabetes in South Africa: the impact of taxing sugar-sweetened beverages. PLoS One. 2015;10(11):e0143050

81. Malawi Ministry of Health. Health Education Services: What We Do. Available from: http:/www.healthpromotion.gov.mw/index.php/whatwe-do. Accessed April 1, 2017.

82. Crawford J, Larsen-Cooper E, Jezman Z, Cunningham SC, Bancroft E. SMS versus voice messaging to deliver $\mathrm{MNCH}$ communication in rural Malawi: assessment of delivery success and user experience. Glob Health Sci Pract. 2014;2(1):35-46.
International Journal of General Medicine

\section{Publish your work in this journal}

The International Journal of General Medicine is an international peer-reviewed open-access journal that focuses on general and internal medicine, pathogenesis, epidemiology, diagnosis, monitoring and treatment protocols. The journal is characterized by the rapid reporting of reviews, original research and clinical studies across all disease areas.

\section{Dovepress}

The manuscript management system is completely online and includes a very quick and fair peer-review system, which is all easy to use. Visit http://www.dovepress.com/testimonials.php to read real quotes from published authors. 